\title{
Using Free and Open Source Tools in Smart Solution Development for the Agriculture Sector in Oman
}

\author{
Vikas Rao Naidu \\ Noof AL Saadi \\ Halima Al Hamdani \\ Eqtibas Al Moqbali \\ Raza Hasan
}

\author{
Middle East College \\ Middle East College \\ Middle East College \\ Middle East College \\ Middle East College
}

\begin{abstract}
Technology is providing support to almost all the sectors around the world. The agriculture sector is also getting greatly benefitted with the advancements in technology. Automation has always been an issue with the various organizations associated with the agriculture sector. But, various organizations have now already started making use of smart technology in order to automate for faster delivery and more accurate results. This research paper also focuses on one such issue related to one of the agriculture based organizations in the Sultanate of Oman. With the advent of some free and open source tools such as LiveCode Community Edition, the development of such a solution has become much easier. The aim of this research is to provide an electronic channel for the user to receive various information and product updates. In order to make sure about the necessity of such system development, the researchers have conducted surveys and interviews among various people. The analysis held that such solution in the agriculture industry can make the operations highly fast along with transactions. Further, the usage of free and open source tools to develop such a solution could be very beneficial to the end users as well as the organizations. Researchers have suggested a methodology that suits the nature of research and the research requirements.
\end{abstract}

\section{Introduction}

This is a research paper for using free and open source tools in smart solution development for the agriculture sector in Oman. So, this research paper includes information about the smart solution development for the agriculture sector in Oman. Also, it includes literature review to seek more information. The paper also includes the results of the questionnaire survey.

\section{Literature review}

An issue is discussed step by step to create the first application. The first step is to get the idea or solve the problem. In this research, we would create the application for the factory because they use paper to complete their work. And, sometimes if they run short the paper, the application would solve the problem and would help them. The second step is to choose/select the need. When we select/decide the need, we would know why we need the application. Also, we should create one page to explain the application. The purpose of this is to draw the attention of the visitor and work on communication through email or phone number. The third step is to specify the specific features. This is done by creating the work needed by people and work on planning the details of the location on the paper to start the design. Planning will help build expectations that could be materialised. The fourth step is the deactivation of non-core objects. The work plan is vital to carry out the research in a proper manner for ensuring the basics work based on the pre defined plans goes well. Step Five includes design. Design is really an important and focus on development comes later. But, actually the issue is how a user use the application. The best thing to do is to design a 


\section{Journal of Student Research}

Fourth Middle East College Student Research Conference, Muscat, Sultanate of Oman

useful design for technology. Step six is to get people with knowledge of design and development. For example, companies that design and develop applications and have full skills and knowledge can be hired. The company can be sure of looking for it because it is very important. Step seven is to sign up for a developer account at app stores. Step eight is collection analytics. It helps to collect information on how to use and keep an application on your phone. The ninth step is to get the opinions and comments of the first customers who used the application.

Through the opinions of customers, one can modify and develop the site. The last step is to display the properties and features that were not displayed at the beginning of the application. This is a very effective step. This article will help me to start to do the application. (Rahul Varshneya, 2014).

Different methodologies have been adopted to cater the problem and to deal with the current situation. Qualitative research is to explore phenomena in a variety of ways. It helps to collect data and information in interviews. Quantitative research is more influential. They are done through structured means instead of exploring or describing things. Quantitative is used in medicine and science and its results are true. Mixed methods are between exploration and hypotheses. This type of method is used in interviews to understand the matter and identify and record observations. It helps others explore topics at different levels and gain different comments and perspectives. This helps to integrate theories and ideas and ethods of methodologies and designs. For example, a design study focuses on exploration and the situation of a person or group of people. Also, anyone can work on compiling information, conducting interviews, or making reports to create a complete picture. In this literature review will help me to select the method. (Jack, 20016).

The methodology chosen to design the final product based on this research is waterfall model as it depends on the previous achievements. For example, a worker cannot deliver the application without payment. It is also considered a repetitive relationship. When performing different operations and one of the operations needs to be developed, this development can be done. The methodology of the waterfall has some problems, including Works on freezing requirements or design specifications in advance. Also, when you do not understand the requirements cannot use the waterfall. Thus, waterfalls are associated with high costs and efforts. Repetition is small, standalone research based on analysis and design. It is also advantageous that he is working on restructuring test wings. Waterfalls help manage costs, detect errors and eliminate them. All methodologies contain negatives and positives. Large research always use waterfalls because they are more accurate. This article will help me to how to use the methodology of the waterfall. (Wilfred Van Casteren, 2017).

Live Code is an free and open source application that contains a different application development language. Network Tracer also helps the user to develop the application. It is also used to send information and correct errors. Vimeo This package consists of 3 modules called one: DB Lib works to speak directly with the information server. The other called Remote DBL works to communicate with PHP which speaks with raw data. Data Storage Lib is a library that can be downloaded over the phone for use 


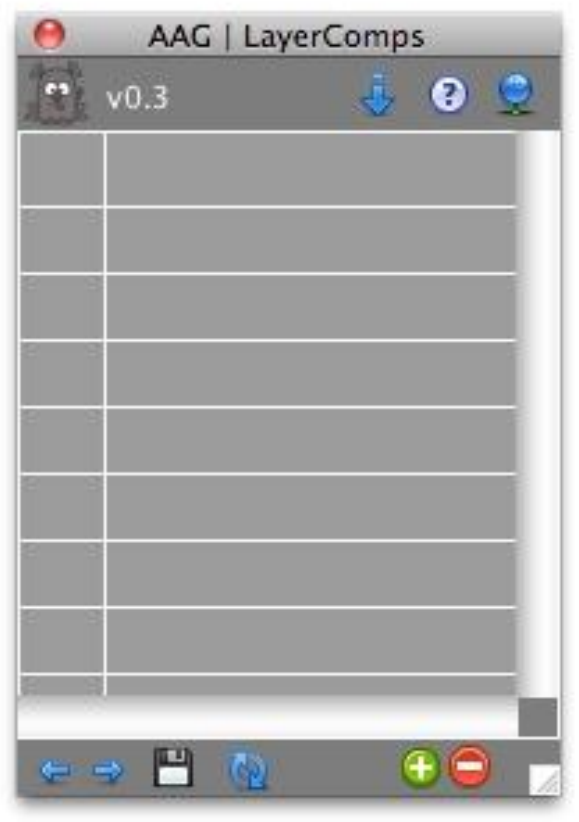

Figure 1. Screenshot of LiveCode

AAG Tools is a set of tools added and used in LiveCode to produce a particular action. LayerComps allows the user to record straight and clear controls and help to switch cases when changed. It is also used in creating various initial layouts to show them to the client and can be easily replaced.

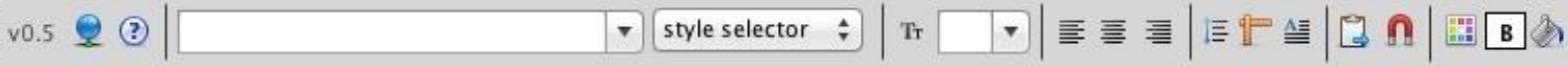

Figure 2. Basic tools of LiveCode

Type tool is an additional component of LiveCode that makes it easy to change properties such as font, colour, stroke, text length, resolution, font colour, and text colour. File Drag is an additional component that makes it easy to add tools by dragging and dropping. This information will help me to use the tools in the application. (Gariz, 2018).

Animal feed is important for animal health, environment and food safety. Examples of food security and safety are close relationship such as Prohibit meat and mammals from mammalian mammals from all farm animal feed. Due to the spread of spongiform encephalopathy in cattle. The work of farmers in feeding animals is based on a variety of factors, including species, age of animals, and type of food, cost and nutritional value of various types of animal feed. Food additives play an important role in modern agriculture. Products used to feed animals to improve the characteristics of feed, for example, add flavour or feed to increase the speed of digestion. When the company wishes to add additional materials, it must take prior permission as it is considered part of the attic. The competent authority shall also examine and verify this additional article. There are several types of materials, including technology such as preservatives, sensory like flavours, food such as vitamins (Parma, 2018).

In figure 3, buttons are used in the commands and functions of the data room. 


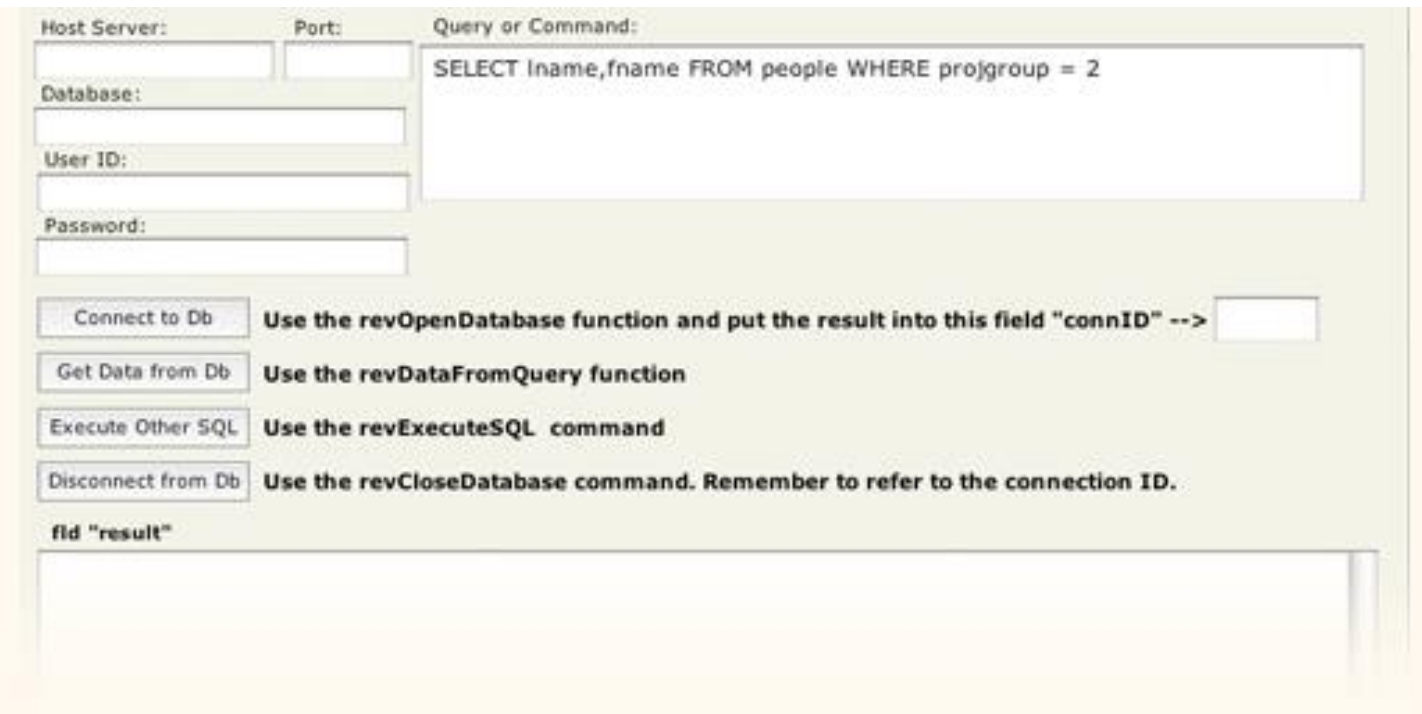

Figure 3. Database options in LiveCode

There are different fields that contain information that creates a connection in the database. There is also a field that can enter SQL data to be executed within the program. Live Code contains a lot of commands that help the developer interact with the databases. There are a lot of tools that work with databases and keep them working. It is hard work for people who use it for the first time there are ways to help learn from them: The first is to open the database and is done by calling the function. When the function is written correctly, the stack is connected to the server. The ID number must be stored in a safe place. The next step is to close the database connection because if the databases are not closed the operation may fail. You must close the database to make sure the contact is valid by calling the function. The next step is to bring the data to LiveCode. The easiest way to do this is to rev Data from Query that sends a SQL query to the data room and returns it. The last step is to execute SQL commands. When the operation succeeds, the function will contain an integer and if an error occurs, an error message will be displayed. In this article will help me to how to connect database with LiveCode. (Jacky, 2016).

According to Gibney, there are a lot of discussions that occur because of the foods products produced by animals. Animal products also depend on foods that feed on them. If the food eaten by the animal is healthy and safe, it will produce healthy food for humans without the disease. However, if animal food is not suitable and safe, it will cause many diseases in humans. Therefore, take into consideration the food given to animals (Gibney, 2012).

\section{Mobile application to support this research}

LiveCode community is a free and open source tool which is proposed to design mobile application based on this research. This tool needs basic knowledge of programming and designing a mobile application is much simpler. Moreover it has in-built database support. Anyone with basic knowledge of Programming Logic can design and develop a mobile application. This program has support for all mobile and desktop environment when it comes to export options. And hence one can directly export and publish the application for different platforms such as Android and IOS.

\section{How databases works}

When using Live Code can communicate with SQL program databases. Data can be obtained from the database. There are some terms used such as field and cursor, which is a standard terminology to work with databases. 


\section{Journal of Student Research}

After that access the database. An external resource that saves the information and organizes a special form for quick access and retrieval. Databases in SQL can be linked with Live Code by going to the menu in Live Code in the database library and opening the dictionary and typing the database in the search field. The SQL program runs on a set of records rather than on individual rows. The recordset generated by SQL is called a database pointer. The SQL feature describes the properties of the records requested by the user instead of processing each record. In this article will help me how the database works in LiveCode and what to do. (Mohammed, 2019).

\section{Result}

The questionnaire is the first tool used when implementing projects. However, the design of the questionnaire is complex and takes time. The quality of the data collected is determined by the quality of the questionnaire used. Using the question-analysis method is also very easy to analyze. By selecting a large group of people and then analyzing the results. So, in this research select more than 50 people. Also, choose people how are will use the application.

\section{Have you ever used any such application before?}

\section{0 responses}

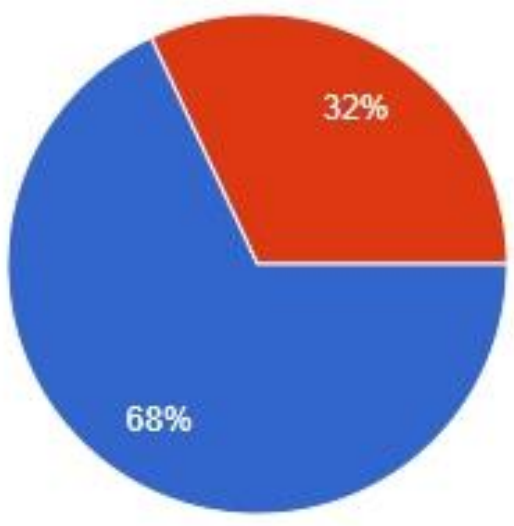

Figure 4. Database analysis chart 1

Figure 4 shows that $68 \%$ of people use like this program. And $32 \%$ of people do not use. So, the high result is for the people to use like this program at this time.

Figure 5. Database analysis chart 2

Figure 5 shows that $61.5 \%$ agrees with the application will help the user to get enough information about the products. And 34.6\% strongly agrees with the application. 3.8\% strongly disagrees with the application. That means the result is the application will help the user.

Figure 6. Database analysis chart 3

Figure 6 shows that most of the people agree for the application will help communicate between 
customer and user. Because 51.9\% selected agree, 40.4\% strongly agree, 5.8\% strongly disagree and $1.9 \%$ disagree. So, that means the majority of the people agrees that this application will be good for communication.

Figure 7. Database analysis chart 4

Figure 7 shows that $84.6 \%$ selected yes for the useful to business and the user. $15.4 \%$ select no the application is not useful to business and the user.

Figure 8. Database analysis chart 5

At this question, $84.6 \%$ responses are in favor. So, the Figure 8 shows that the customer will use the application. $15.4 \%$ of the customer does not use the application.

Figure 9. Database analysis chart 6

$84.6 \%$ of the people choosen yes. So the Figure 9 shows that, the user should finds the application easy to understand and use.

In the end, most of the people are agree with the application because it is easy to use and easy to communicate with the customer. Also, these people use a different application like this and they are having different information about the program. But other people don't like to use the application because they have no confidence in the programs. Also, on an open question, some people write:

"The app should be easy to use. Also, include all services needed by the user. Apply for different payment processes, Put the image and product value, provide appropriate services and prices and another one say all of the things are available."

\section{Conclusion}

From this study, it is clear that such research is required for the agriculture sector in Oman from time to time. At present we do not have any mobile applications which are providing sufficient guidelines for the cattle feeds and how the quality could affect the food products that the human being is dependent on. Almost entire world has started using smart devices and even people in agriculture sector uses smart devices for communication. Hence, implementation of such solution will not be difficult.

\section{Acknowledgement}

We would like to express thanks to God almighty for abundant blessings because of which this research has taken its shape. Sincere thanks to the family members who have always supported while carrying out the tasks. Finally from the bottom of the heart, the authors would thank the management, staff, and friends at the Middle East College.

\section{Reference}

Casteren, W. V., 2017. The Waterfall Model and Agile Methodologies. A comparison by project characteristics, 2(2), pp. 1-3. 


\section{Journal of Student Research}

Fourth Middle East College Student Research Conference, Muscat, Sultanate of Oman

Ghen, 2017. Types-methodologies. [Online] Available at: https://classroom.synonym.com/differenttypes-methodologies-7459438.html [Accessed 30 april 2019].

Gariz, n., 2018. LiveCode Advanced Application. LiveCode project, 9(4), pp. 2-11.

Gariz, n., 2018. LiveCode Advanced Application Architecture book. LiveCode Projects, 9(12), pp. 3-11.

Jacky, 2014. Project Management. [Online] Available at: https://www.brighthubpm.com/projectplanning/56372-types-of-feasibility-studies/ [Accessed 4 May 2019].

Kramer, 2015. entrepreneur. [Online] Available at: https://www.entrepreneur.com/article/231145 [Accessed 29 april 2019].

Michaelbierman, 2015. Feasibility study. [Online] Available at: https://www.myaccountingcourse.com/accounting-dictionary/feasibility-study [Accessed 4 May 2019].

Parma, 2018. Animal feed. Feed additives, 10(8), pp. 11-15.

Gibney, M., 2012. Food from healthy animals. Healthy food from healthy animals, 12(9), pp. 25-26.

Nick Antonaccio (2016) Livecode Tutorial. available at:

https://www.youtube.com/watch?v=ZRoGo7nOXrw (accessed 3 may 2019)

Al Badai, N., Al Ajmi, Z., and Naidu, V.R. (2017) Effectiveness of Open Educational Resources for Enhanced Learning In Flipped Classroom. in ICERI2017 Proceedings. held 2017

Naidu, V.R., Al Balushi, H., and Bhatia, S. (2017) Effectiveness of Free \& Open Source Tools to Enhance Game Based Learning Experience in School Education. in EDULEARN17 Proceedings. held 2017

Naidu, V.R., Singh, B., Al Harrasi, R.A., and Al Balushi, H.H. (2017) Technology Enhanced Learning Assisted by Free and Open Source Software. IJAEDU- International E-Journal of Advances in Education

Mohammed, Q.A., Naidu, V.R., Hasan, R., Mustafa, M., and Jesrani, K.A. (2019) Digital Education Using Free and Open Source Tools to Enhance Collaborative Learning. IJAEDU- International EJournal of Advances in Education 